\title{
Review Symposium of
}

Cheap Sex: The Transformation of Men, Marriage, and Monogamy

\author{
By Mark Regnerus \\ Oxford University Press, 2017 \\ Tristan Bridges \\ Department of Sociology \\ University of California, Santa Barbara \\ Paula England \\ Department of Sociology \\ New York University \\ Barbara J. King \\ Department of Anthropology \\ College of William and Mary \\ Philip N. Cohen \\ Department of Sociology \\ University of Maryland
}

January 2018

Note: These are preprint versions of this review symposium forthcoming in Men and Masculinities. The authors are listed in the order in which the reviews will be published. 


\section{Symposium Introduction by Tristan Bridges}

Mark Regnerus has never published in Men and Masculinities. And I would be surprised to hear that he had ever submitted anything for consideration. And the book reviewed in this symposium, Cheap Sex: The Transformation of Men, Marriage, and Monogamy, pursues claims that have been made before. It shares common ground with books like Lionel Tiger's (1969) Men in Groups, Steven Rhodes’s (2004) Taking Sex Differences Seriously, Robin Baker's Sperm Wars (2006), Randy Thornhill and Craig Palmer's (2000) A Natural History of Rape, and John Gray’s (1992) Women Are from Venus, Men Are from Mars written (in order) by an anthropologist, a political scientist, two biologists, another anthropologist, and a pop psychologist. All this is to say that this is an argument produced by a diversity of (often) men across a wild variety of disciplines and throughout popular culture. Importantly, the arguments in each have also been challenged and subjected to sustained criticism within each discipline as well. But I have no doubts that Regnerus's iteration will be followed by others.

Politically, Regnerus suggests that the current crisis of the family is that women say "yes" far too often and easily. On the face of things, this claim contrasts sharply with Thornhill and Palmer's (2000) scandalous use of evolutionary psychology to suggest that men would not have to turn to rape if only women said "yes" more often. There is a contradiction even among those leaning on evolutionary psychological claims. What these claims share in common is that women are presented as at fault. Research relying on evolutionary psychology is steeped in lending pseudo-scientific credence to bromides that play on stereotypes of gendered actors and action. In Cheap Sex, Regnerus joins an interdisciplinary collection of authors subject to this critique.

Cheap Sex is a book about masculinity, gender, sexuality, family, inequality, and more. In it, Regnerus makes bold claims about the fate of marriage and the family, men's and women's sexual desires, normative claims about what those desires ought to be, and how transformations in what he frames as a world historically constant (until now) arrangement between women and men has shifted a delicate balance of power further in men's favor as women demand less from men in exchange for sex. The questions pursued in Cheap Sex are not new, and neither are the answers. So, you might ask, why review it?

I hope that the symposium is useful as scholars from a range of disciplines who might consider the book of interest seek to make sense of Regnerus's argument and what he frames as discoveries. Beyond this, reflections on this book offer an opportunity to consider how we have navigated similar arguments in the past and what we can learn from that work. Toward those 
ends, I invited a group of scholars to assess Cheap Sex, the theoretical framework on which the argument rests, the facts upon which it is based, and the use of evolutionary psychology and biological determinism necessary to make sense of this argument. I invited sociologist Paula England to assess Regnerus's use of and reliance upon exchange theory, applied to sexual relationships and sexual exchange. I asked anthropologist and NPR science blogger, Barbara J. King, to evaluate the biologically deterministic and evolutionary arguments made in the book. And I invited sociologist Philip Cohen to consider the data Regnerus marshals to support the theoretical contribution he proposes. All three examine Cheap Sex from different angles and address different kinds of flaws with the book. I hope this collective consideration of the text produces new dialogue as we continue to challenge an old argument.

\section{References}

Baker, Robin. 2006. Sperm Wars: Infidelity, Sexual Conflict, and Other Bedroom Battles. New York, NY: Thunder's Mouth Press.

Gray, John. 1992. Women Are from Venus, Men Are from Mars: A Practical Guide to Improving Communication and Getting What You Want in Your Relationships. New York, NY: HarperCollins Publishers, Inc.

Rhodes, Steven. 2004. Taking Sex Differences Seriously. San Francisco, CA: Encounter Books.

Thorne, Randy and Craig T. Palmer. 2000. A Natural History of Rape: Biological Bases of Sexual Coercion. Cambridge, MA: The MIT Press.

Tiger, Lionel. 1969. Men in Groups. New York, NY: Random House. 


\section{Review by Paula England}

Cheap Sex is about unintended consequences of the sexual revolution, which Regnerus attributes to the availability of birth control starting in the 1960s. His key claim is that men's easier access to sex has made it more difficult for those women who want committed, monogamous relationships to find partners for that package deal.

Unlike many of his fellow sociologists, Regnerus believes that there are biological differences between men and women in how much their behavior is motivated by the desire for sexual satisfaction. I am less sure how much of this difference is "hard wired," and how much comes from the cultural sexual double standard that shames women for nonrelational sex while giving men high fives.

Regnerus deploys ideas from exchange theory in sociology and market theories from economics. In this view, if I have something a man wants, I can get something from him in exchange for giving him what he wants. The more he wants it, the more I can get. But what I can get is decreased if he has alternative partners who will give it with fewer conditions. Applied to sex, Regnerus reasons that, because men want sex more than women, women will get something from men in return for sex. Traditionally this has been economic support and a committed relationship. A further implication is that what one woman can expect to get from her sexual partners depends on the conditions other women are putting on having sex.

When the birth control pill became available in the 1960s, it lessened the risk of pregnancy associated with sex. By allowing couples to have premarital sex with little fear of pregnancy, the pill led more women to delay marriage long enough to finish college and start a career. The gender revolution emanating from women's employment benefitted many, and Regnerus recognizes this, but he highlights negative consequences of birth control and women's economic empowerment for some women. In this vein, his key point is that, because some women responded to the reduced risk of pregnancy with freer sex, sex became "cheaper" for men, and this lessened the ability of other women to find men willing to make some relational commitment before sex. Regnerus suggests this is for two reasons. First, the market/exchange theory implies that fewer men will now commit to exclusive relationships because, unlike the men of earlier eras, they can find women who will have sex with them with no such strings. Second, the cultural piece is that, once a lot of people are having noncommittal sex, the statistical norm becomes morally accepted; a woman holding out for a serious commitment before having sex is now as likely to face peer pressure to drop her prudery as to be seen as morally admirable. 
Regnerus also believes that the internet encourages “cheap sex.” He argues that sites such as Tinder allow people to find casual partners more efficiently, and men's online pornography use combines with masturbation to compete with real women. All this, in his view, means that women are less likely to get the commitment of a durable relationship when they want it from men. He forecasts that men may become less monogamous in marriages.

Regnerus' book is full of analysis of a recent survey he conducted, and contains quotes from qualitative interviews his team conducted. Some of this material is fascinating, but it is important to note that it is not evidence for his main thesis, because the thesis is about change over a period of over 50 years, whereas his survey data are contemporary. In fact, his central claims, as sketched above, are quite speculative. Thus, should we believe his central claim that some women's newfound willingness to have sex with fewer relational conditions adversely affects other women's ability to find men who will commit to them and be monogamous? Because I find the basic tenets of exchange theory sensible, I agree that, other things equal, it is a plausible hypothesis. But other things aren't equal because, due to birth control and many other factors, women have gained economic power relative to men since the 1960s; more are employed, and their earnings are higher. Regnerus deploys exchange theory but fails to notice its implication that women's higher earnings should help women get more of what they want in their relationships with men. According to exchange theory, women's earnings should lead dating women to be more able to get men to commit to exclusivity, if that is what they want. The earnings of cohabiting women should increase the control they have over the timing of moving to marriage. If a man is seeing a woman he likes, and she is pressing for more commitment, wouldn't her implicit offer to share more of her earnings with him as they move to a more committed relationship make the relationship more compelling to him?

Yet I think Regnerus is correct in the claim that it is more common for women than men to be the partner frustrated in their attempts to move a relationship up a notch in commitment. Although quantitative data are unclear on this, my read of recent qualitative studies (e.g., Sassler and Miller 2017) is that this is the more typical direction of gender mismatch. But because his own assumptions and preferred theory could just as likely have predicted women's increased rather than decreased ability to procure commitment from men, I'm not convinced that he has given us the correct explanation of this gender conflict.

Men are often dictating the terms and timing of their relationships, but I suggest we look elsewhere for explanations. Perhaps it is not the gender revolution but its incompleteness and stall that is the explanation (England 2010). Or perhaps we need new theories and insights. 


\section{References}

Cook, Karen S., ed. 1987. Social Exchange Theory. Beverly Hills: Sage.

England, Paula. 2010. “The Gender Revolution: Uneven and Stalled.” Gender \& Society 24, 2:149-166.

Sassler, Sharon and Amanda Miller. 2017. Cohabitation Nation: Gender, Class, and the Remaking of Relationships. Berkeley: University of California Press. 


\section{Review by Barbara J. King}

In Cheap Sex, Mark Regnerus uses data from the Relationships in America Survey commissioned by the Austin Institute for Family and Culture that he helps run and from interviews with 100 people that he selected, to explain the collapse of monogamy and marriage in the US today and how these changes harm us all. Regnerus relies heavily on the exchange model of mating, which holds that women use sex to get resources from men, a view "rooted in stable realities about male-female differences that are not socially constructed and will not disappear." Men are wired for sex, women to be gatekeepers of sex, but now, Regnerus explains, women give away sex too readily.

When is sex cheap? According to Regnerus, it's cheap if "women expect little in return for it and if men do not have to supply much time, attention, resources, recognition, or fidelity in order to experience it.” This tendency for what Regnerus also refers to as a "pure relationship” that's about the individual's will rather than an enduring bond has emerged primarily because of new freedoms associated with the Pill and women's wage-earning abilities, with the impossible erotic standards created by the porn to which men are now nearly addicted, and with the sad failure of us women to value ourselves properly. Again, according to Regnerus.

Regnerus doesn't just lean heavily on quotes from his chosen interviewees to support his thesis. He chastises those interviewees_-indeed he chastises most of us_-for failing to grasp what he has figured out. Women "seldom even recognize the quandary they are in" regarding cheap sex, he writes. Even as he judges, he also advises: he suggests to a former graduate student that her friend, wishing marriage, should embark on a "sex strike” with her current boyfriend.

From the perspective of anthropology and the evolution of gender, I offer three primary ways in which Regnerus has got things wrong.

Regnerus describes monogamy and pair bonds as "clearly old, biologically rooted realities.” Yet there's no convincing evidence to suggest that these structures characterized the mating of our hominin ancestors. Certainly, some models claim a pair-bonded past in which males were producers and women were baby-makers in a straightforward exchange view of human evolution. But these have been revealed by Fedigan (1986) to harbor numerous flaws, including hidden (and inaccurate) assumptions about our past. None of our closest living relatives, the chimpanzee, bonobo, gorilla, or orangutan, are monogamous. Regnerus himself acknowledges that "monogamous arrangements comprise a historical minority of the globe's societies” but presents monogamy as a prerequisite for a society to "flourish.” 
Just as biologically determinist is Regnerus's stance on the dichotomy between women's and men's evolved psychologies. "Very little about XX and XY are new," he declares. Men are "powerfully motivated by competition in sports and business," for instance, and "Women's level of interest in casual sex with a stranger is far lower than men's.” Fine (2017: 56) critiques this latter type of conclusion, however. In experimental studies, women do indeed respond differently to offers of casual sex than do men, but as Fine writes, "Social realities mean that women and men in these studies are simply not participating in the same experiment.” The risk of physical harm to women in casual-sex encounters is real, and there's the risk too of being considered "a slut," as Fine puts it. When the experiment is altered to ask about casual sex not with a stranger but instead with a celebrity or close friend, the sex differences disappear.

A third problem is that that the categories Regnerus deploys are sociologically inaccurate substitutes for the complexity of gender and sexual orientation in the world. Not all women have XX chromosomes, nor all men XY. Transgender women (including those with XY chromosomes) are women, and transgender men (including those with XX chromosomes) are men. Almost 2\% of the population is estimated to be intersex (including people with other than XX or XY chromosomes). As Fausto-Sterling (2000: 76) says, we now know that “complete maleness and complete femaleness represent the extreme ends” of a spectrum.

Turning to sexual orientation, Regnerus includes what he refers to as "non-heterosexual people” or "sexual minorities" in his analysis—-that is, gays, lesbians, and bisexuals. These categories almost always appear fixed in the text because Regnerus has missed the reality that people may fit all along a sexual spectrum, including at asexual and pansexual locations.

Additionally, in a volume touted as evidence-based (though I question the quality of the data), it's disturbing that Regnerus drops in claims without any evidence whatsoever. People who aren’t religious, for instance, he decides dwell in a world “emptier and less mysterious.”

Regnerus tries to deflect anticipated criticism by suggesting that skeptics of his conclusions are mired in liberal ideology. But this is not the cause of my skepticism: what went awry with the peer-review process at Oxford University Press I can't know, but it’s precisely in the arena of good, reliable scholarship in which Cheap Sex fails. Readers who know Regnerus's 2012 study purporting to show that children of sex-same parents are disadvantaged compared to children raised in a mother-father household—and the outcry about it including a letter of substantive concerns signed by 200 researchers and a formal reprimand by the journal in which he published-might have a trust issue even before opening Cheap Sex. Certainly I suspect that many readers will experience (or retain) that issue by the time they close its covers. 
At the same time, the issue goes far beyond that of academic scholarship into the arena of human rights. In a time when "sexual minorities” like LGBTQI+ people are fighting not just for respect and legal protection but also against bodily violence in rising hate crimes, Regnerus's suggestion that they somehow undermine the fabric of morality in this country is dangerous. And have no doubt, he does very much suggest this when he cites the exchange relationship as "heteronormative" and links "non-heterosexuals" with the "cheap sex" that he fears will ruin us all.

\section{References}

Fausto-Sterling, Anne. 2000. Sexing the Body: Gender Politics and the Construction of Sexuality. New York: Basic Books.

Fedigan, Linda. 1986. The changing role of women in human evolution models. Annual Review of Anthropology 15: 25-66.

Fine, Cordelia. 2017. Testosterone Rex: Myths of Sex, Science, and Society. New York: W. W. Norton \& Co. 


\section{Review by Philp N. Cohen}

Cheap Sex is an awful book that no one needs to read. The book is an extended rant on the theme, "Why buy the cow when you can get the milk for free?" wrapped in a misogynist theory about sexual exchange masquerading as economics, and motivated by the author's misogynist religious and political views.

Regnerus is a sociologist with a documented record of both academic dishonesty and poor quality research, a history I have summarized elsewhere (Cohen 2018a). Given this history, I asked for a copy of the main dataset he used, the Relationships in America survey, to verify his analyses. Despite his public promise that the data would be made available in 2015, my request was refused. Therefore, I do not accept as evidence the results he reports in this book since they are not subject to verification. Here I review the quality of his theory, arguments, and the methods he describes himself using. (Some of these comments are distilled from complete notes I posted in [Cohen 2018b]).

Regnerus starts from the observation that "men want more sex than women do, on average.” In a fatal crime against logic, he immediately transforms that difference in central tendency into a theory of opposites in a system of exchange. "Economically speaking ... women have what men want. ... So in the heterosexual mating market broadly understood, there is demand - interested men - and supply: women” (pp. 24-25). The imbalance in sexual desire between men and women is not a recent phase or modern innovation, in his view. Rather, it is a fixed quality of human nature, and this exchange dynamic is thus "rooted in stable realities about male-female differences that are not socially constructed and will not disappear" (44).

"Sex is cheap," Regnerus writes, in the closest he gets to a definition, "if women expect little in return in return for it and if men do not have to supply much time, attention, resources, recognition, or fidelity in order to experience it” (28). The "price” of sex only refers to what men pay for it; the "exchange" is men buying, and women selling. In fact, he states categorically (and of course falsely), “women never pay men for sex” (24).

The practice of women allowing men to have their sex without a promise of marriagemade possible because women now have the Pill and jobs-goes against all of human history, and undermines men's motivation to accumulate resources and achieve higher status, which they used to need to obtain that which they most desire. Hence, "Kendalia, a 32-year-old African American woman from Milwaukee cohabiting with an unemployed man who spends most of his days playing video games and watching pornography” (50). She is already giving him sex (if not quite enough), so why should he get off the couch? 
With loose women, pornography, and masturbation (“arguably at an all-time high” [138]) sapping men's will to either succeed or marry, Regnerus sees a rapid descent into moral crisis, epitomized by rampant homosexual behavior - which is not to be confused with homosexuality itself, something he never concedes exists naturally. "Just because someone self-identifies as something other than heterosexual," he writes, “does not mean they are able to just opt out of deeply embedded sexual differences in socio-sexual behavior” (82). The moral crisis is now, tragically in his view, institutionalized through the legal recognition of same-sex marriage (which Regnerus strenuously, if haplessly, opposed as an expert witness in the courts).

The deep misogyny in Regnerus's thinking is apparent in his description of women's responsibility for modern moral decay. "Remember," he intones. "Sex is her resource, and in a consensual relationship she controls access to it. It doesn't happen if she doesn't permit it” (95). Of course, the definition of "consensual” means sex would only happen if both partners "permit it,” but such obvious logical errors are no match for Regnerus's ideological blinders.

Regnerus reports that he and his team did 100 interviews of young adults. However, the book contains no systematic information about them, or information on how they were sampled or interviewed (although he does mention the race of several who are not White). Very few of are quoted, and in those cases they usually serve either to repeat his conclusions back to him or as objects of his contempt. For example, he quotes a 25-year-old woman as saying, "relationships are more casual than they used to be ... So I think now that may, maybe it's because women have taken on a stronger role in both relationships and, and pretty much everywhere that that might have something to do with it” (96). This is a restatement of Regnerus's thesis.

In the most egregious case of showing contempt for his respondents, he scoffs that one woman's "high hopes for enduring marriage seem noble," but she has “disdain for dependence upon a husband” and "knee-jerk criteria for leaving.” What are those "knee-jerk criteria”? She is quoted as saying, "Maybe one day my husband will fall in love with somebody else. What am I gonna do? Or he cheats on me or he hits me. You know, then I'm gonna have to get out” (159).

In addition to the reported interviews, Regnerus offers some cursory analysis of the surveys he commissioned. This includes a few descriptive statistics, and regressions with variables coded in ways that are not disclosed, so the reader cannot evaluate the models. There is also some shameless $p$-hacking, most obviously in his use of an asterisk to indicate $p<.10$ instead of the conventional $p<.05$, without explanation. In one egregious case he adds several control variables to a model, producing no change in the coefficient of interest, but the asterisk disappears, leading him to declare triumphantly that the original variable "no longer matters" (7780). 
The book suffers from poor writing and copy editing that makes it hard to follow the arguments. For example, he repeatedly misuses the word "predictable." He refers to mating markets in the old days as a time when there were "roughly equal numbers of men and women, whose bargaining positions - averaged together - were roughly comparable and predictable” (35) - a nonsensical pile of words. Elsewhere, he refers to relationships as "growing increasingly predictable,” when he is actually describing an increase in diversity, which means they are less predictable (5); and then later he writes, of the trend away from heteronormativity, "the effect of it on mating market dynamics is almost certain, but it is not simple to predict,” without recognizing that "certain” things are by definition "simple to predict" (60). Another problematic word is "it," which readers will tire of chasing around in passages such as this: "We are simply

not free to write off fertility's debt to love, its desire for exclusivity, and its idealization of marital union. It will resist and reemerge, if even only in wounded form” (184).

There are true things in this book. For example, the Pill has had a large effect on sexuality, women's advancement and cultural adaptation have contributed to the decline of marriage, and pornography has corrosive effects on some people's relationships. These are not new here, nor are they advanced in Regnerus's telling. Readers interested in these topics should look elsewhere.

\section{References}

Cohen, Philip N. 2018a. Enduring Bonds: Inequality, Marriage, Parenting, and Everything Else That Makes Families Great and Terrible. Oakland, California: University of California Press. Cohen, Philip N. 2018b. “Notes for a Review of 'Cheap Sex,' by Mark Regnerus.” Family Inequality (blog). January 5. https://familyinequality.wordpress.com/2018/01/05/notes-for-areview-of-cheap-sex-by-mark-regnerus/. 